\title{
OPTIMIZATION OF EDDY CURRENT FLOW METER PERFORMANCE
}

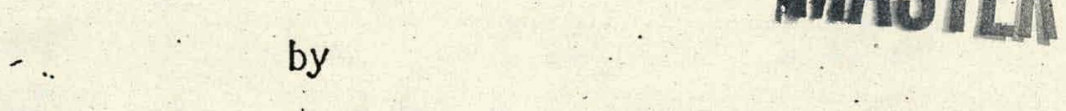

James R. Sheff

Delbert L. Lèssor

To be presented at the 1972 Annual Meeting of the American Nuclear Society, June 18-22, 1972, at Las Vegas, Nevada.

\section{Battelle Memorial Institute}

Pacific Northwest Laboratory

Work performed for the U. S. Atomic Energy Commission under work order from Westinghouse Hanford Company, a subsidiary of Westinghouse Electric Corporation. 


\section{DISCLAIMER}

This report was prepared as an account of work sponsored by an agency of the United States Government. Neither the United States Government nor any agency Thereof, nor any of their employees, makes any warranty, express or implied, or assumes any legal liability or responsibility for the accuracy, completeness, or usefulness of any information, apparatus, product, or process disclosed, or represents that its use would not infringe privately owned rights. Reference herein to any specific commercial product, process, or service by trade name, trademark, manufacturer, or otherwise does not necessarily constitute or imply its endorsement, recommendation, or favoring by the United States Government or any agency thereof. The views and opinions of authors expressed herein do not necessarily state or reflect those of the United States Government or any agency thereof. 


\section{DISCLAIMER}

Portions of this document may be illegible in electronic image products. Images are produced from the best available original document. 


\section{Optimization of Eddy Current Flow Meter Performance}

Analytical methods which describe the performance of an eddy current flow meter in a liquid sodium fast reactor environment were developed and applied. The flowmeter performance was optimized for both flow measurement and bubble detection sensitivity. A flowmeter sufficiently sensitive to bubbles is an important component of a failed element detection and location system for liquid metal fast reactors.

The analytical attack on the problem is a departure from the usual experimental approach to eddy current flow meter. design and testing, and shows that analysis can be a valuable aid to improved performance. The analysis has been tilo-pronged: (1) A numerical solution is calculated for an exact description of a cylindrically symetric meter, and 2) emf perturbations from small defects (bubbles) are calculated using the exact solutions.

Maxwell's Equations for a rotationally symmetric system are solved numericaliy utilizing an iterative method employing several accelerated convergence techniques. Driving coils, stationary conductors, ferromagnetic materials, and axially flowing conductors can be handled. .This is an extension of EDDY* incorporating conductor flow terms and more logic for speeding up solutions.

An expression for perturbations in the secondary coil emf due to bubble passage has been developed." This is an extension of the expression of Burroughst to include conductivity defects (bubbles) located in moving conductors and moving with the conductor.

The basic effect of sodium flow upon the meter can be described as a conductor moving with velocity $\underline{v}$ with respect to the meter in which 
the electric field is E and magnetic field is $\underline{B}$. The current density $\underline{J}$ is given by

$$
\underline{J}=\sigma(\underline{E}+\underline{v} \times \underline{B})
$$

where $\sigma$ is conductivity. Eq (1) is used to eliminate current density from Maxwe11's equations. Assuming linear material relations, the azimuthal component of $A$ for frequencies of interest satisfies

$$
\frac{\partial^{2} A}{\alpha z^{2}}+\frac{1}{r} \frac{\partial A}{\partial r}+\frac{\partial^{2} A}{\partial z^{2}}-\frac{A}{r^{2}}=-\mu J_{\text {applied }}+i \omega \mu \sigma A
$$

$$
+\sigma v \mu \frac{\partial A}{\partial z}-\mu \frac{\partial}{\partial r}\left(\frac{l}{\mu}\right) \frac{1}{r} \frac{\partial(r A)}{\partial r}-\mu \frac{\partial}{\partial z}\left(\frac{l}{\mu}\right) \frac{\partial A}{\partial z}
$$

where $v$ is magnitude of the purely axial velocity. This equation differs from that of Tunstall and Dodd* by the presence of the term proportional to conductor flow velocity $v$, but it is an all important difference because this term and oniy this term gives the effect of interest in a flowmeter. Emf's in secondaries are arranged to cancel in the absence of flow. Finite difference approximations allow solution of this equation.

The emf in secondary coils can be deduced from the resulting A field. The emf in flowmeter secondaries is computed as a function of driving current frequency, flow velocity, and eventually flow profile. The magnitude of the resulting $A$ field is shown in Figure 1 for the Fast Test Reactor (FTR) flow meter. Calculations at various frequencies yield the optimum frequency for flow measurement. When the flow profile and conductivity are available as a function of temperature, temperature effects in the emf vs. flow velocity will also be calculated.

Secondary coil response to bubbles comes from change in electrical current near bubbles. The current changes because the ambient electric 
field changes and the bubble moves. Sensitivity of the secondary coil emf to bubbles is calculated from these considerations using the numerically calculated A fields.

In summary, a combination of numerical and perturbation theory solutions of the equations describing eddy current flowneters has provided a means for optimizing flowmeter response to flow and bubble detection.

*. Nelson Tunstall and C. V. Dodd, III. A Computer Program to Solve Eddy-Current Problems, Union Carbide Corporation Nuclear Division. Oak Ridge Gaseous Diffusion Plant; Oak Ridge, Tenn. K-1740, Apri] 8, 1968.

'M. L. Burroughs. A Theory of Eddy-Current Flaw Detection, University of Michigan, Ph.D. dissertation, University HicrofiTms, Inc., Ann Arbor, Michigan, 1964. 


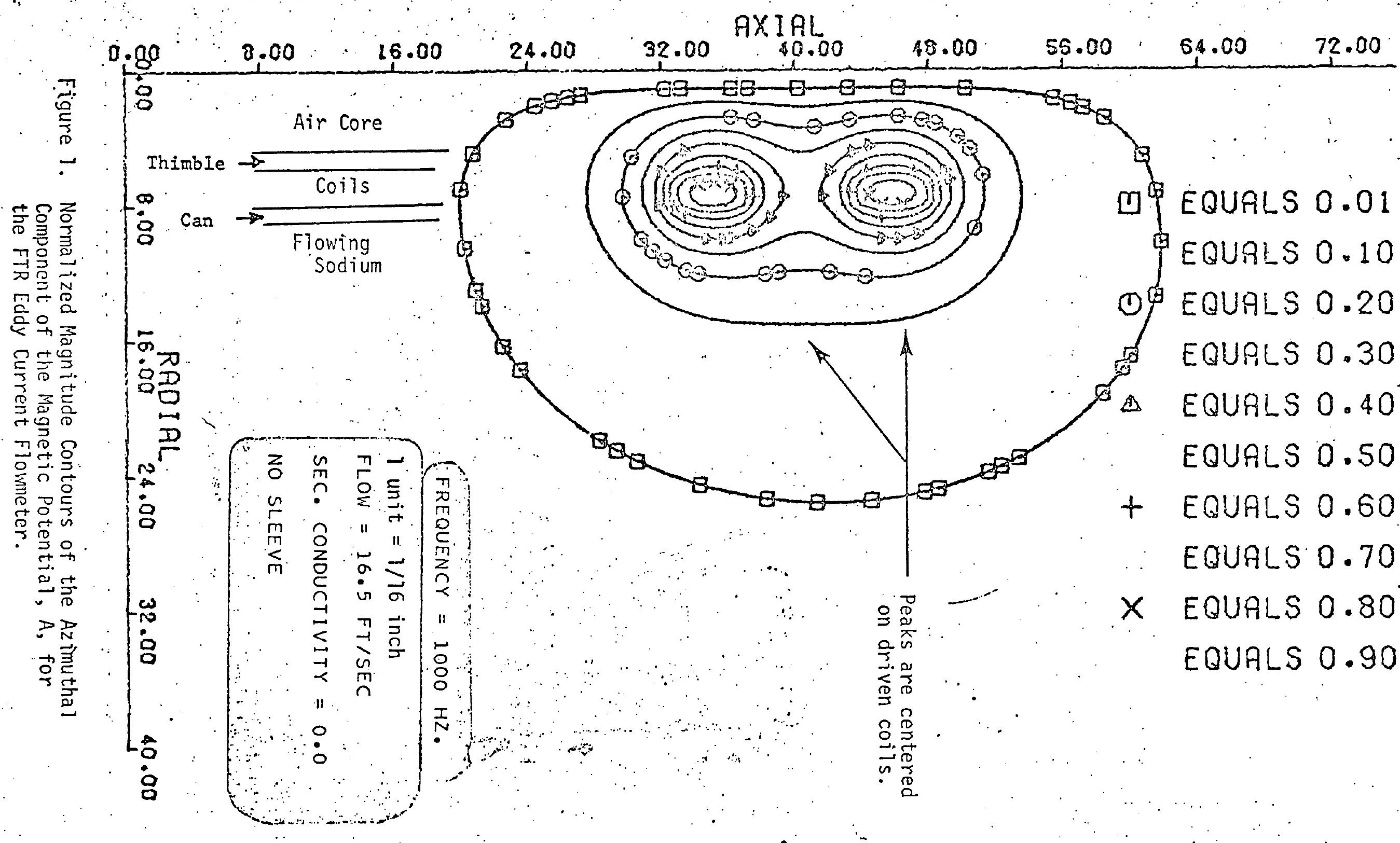

